\title{
Time to scale up molecular surveillance for anti-malarial drug resistance in sub-saharan Africa
}

\author{
Christian Nsanzabana ${ }^{1,2^{*}}$ (D)
}

\begin{abstract}
Artemisinin resistance has emerged and spread in the Greater Mekong Sub-region (GMS), followed by artemisininbased combination therapy failure, due to both artemisinin and partner drug resistance. More worrying, artemisinin resistance has been recently reported and confirmed in Rwanda. Therefore, there is an urgent need to strengthen surveillance systems beyond the GMS to track the emergence or spread of artemisinin and partner drug resistance in other endemic settings. Currently, anti-malarial drug efficacy is monitored primarily through therapeutic efficacy studies (TES). Even though essential for anti-malarial drug policy change, these studies are difficult to conduct, expensive, and may not detect the early emergence of resistance. Additionally, results from TES may take years to be available to the stakeholders, jeopardizing their usefulness. Molecular markers are additional and useful tools to monitor anti-malarial drug resistance, as samples collected on dried blood spots are sufficient to monitor known and validated molecular markers of resistance, and could help detecting and monitoring the early emergence of resistance. However, molecular markers are not monitored systematically by national malaria control programmes, and are often assessed in research studies, but not in routine surveillance. The implementation of molecular markers as a routine tool for anti-malarial drug resistance surveillance could greatly improve surveillance of anti-malarial drug efficacy, making it possible to detect resistance before it translates to treatment failures. When possible, ex vivo assays should be included as their data could be useful complementary, especially when no molecular markers are validated.
\end{abstract}

\section{Background}

The development of resistance to the currently used antimalarial drugs is threatening the major gains in malaria control and elimination made over the last decade. Artemisinin resistance, defined as delayed parasite clearance following treatment with artemisinin monotherapies or artemisinin-based combination therapy (ACT), has been associated with specific mutations in the Plasmodium falciparum kelch 13 gene (Pfk13) [1]. Those validated molecular markers were initially observed in the Greater Mekong Sub-region (GMS), followed by ACT

\footnotetext{
*Correspondence: christian.nsanzabana@swisstph.ch

1 Department of Medicine, Swiss Tropical and Public Health Institute, Socinstrasse 57, 4002 Basel, Switzerland

Full list of author information is available at the end of the article
}

failures due to both artemisinin and partner drug resistance [2-9]. The recent reports of a validated molecular marker of artemisinin resistance in Rwanda [10, 11], and its association with delayed parasite clearance [12], are a major threat to malaria control and elimination in sub-Saharan Africa. Even though the continuous high efficacy of the first- and second-line anti-malarial drugs (artemether-lumefantrine and dihydroartemisinin-piperaquine) in Rwanda is reassuring, an improved scheme for monitoring anti-malarial drug resistance is warranted to mitigate the spread of artemisinin resistance, and ACT failure. Currently, the World Health Organization (WHO) recommends therapeutic efficacy studies (TES) for monitoring drug efficacy and resistance [13], whereas molecular markers and ex vivo monitoring are optional. There is no doubt that anti-malarial drug policy change original author(s) and the source, provide a link to the Creative Commons licence, and indicate if changes were made. The images or other third party material in this article are included in the article's Creative Commons licence, unless indicated otherwise in a credit line to the material. If material is not included in the article's Creative Commons licence and your intended use is not permitted by statutory regulation or exceeds the permitted use, you will need to obtain permission directly from the copyright holder. To view a copy of this licence, visit http://creativecommons.org/licenses/by/4.0/. The Creative Commons Public Domain Dedication waiver (http://creativeco mmons.org/publicdomain/zero/1.0/) applies to the data made available in this article, unless otherwise stated in a credit line to the data. 
should be based on TES results; however, molecular and ex vivo data have played an important role in confirming and monitoring artemisinin and partner drug resistance in the GMS [3, 9, 14, 15]. Indeed, partial resistance to artemisinin is difficult to assess in vivo, especially in high transmission settings where acquired immunity is a major confounding factor [16-18]. Moreover, TES are time and resources consuming, and may be difficult to conduct in low transmission settings, where the risk of de novo emergence of resistance is highest [19-21], due to the low number of patients.

\section{Molecular markers as early warning tools}

Molecular markers offer an additional strategy to monitor the early emergence and spread of anti-malarial drug resistance, are not impacted by host immunity, and may be more cost effective when implemented for routine surveillance. Retrospectively, it has been suggested that partial sulfadoxine-pyrimethamine resistance had multiple origins including areas of high transmission in Eastern Africa [22, 23] and, interestingly, the same region seems to be a hotspot for partial artemisinin resistance $[12,24]$. Today, tools (molecular markers) to closely monitor the early emergence and spread of artemisinin and partner drug resistance are available. This knowledge should be used to establish a comprehensive molecular surveillance system to avoid the mistakes from the past, when the spread of resistance to anti-malarial monotherapies has been detected at a late stage, contributing to thousands of deaths in the meantime. Molecular markers cannot predict treatment outcome at an individual level, however their increase often precedes that of treatment failures [25]. While monitoring Pfk13 mutations is of paramount importance, monitoring partner drug resistance molecular markers is also crucial [26]. Indeed, high prevalence of $P f k 13$ validated molecular markers is not usually associated with treatment failure [27], as evidenced by recent data from Rwanda where the efficacy of both first and second-line treatments is still high despite the increasing prevalence of the $P f k 13561 \mathrm{H}$ mutation (Table 1). Currently, molecular surveillance is often done retrospectively based on convenience sampling, and does not provide an accurate estimation of resistance on a national or sub-regional level. For example, when looking at available molecular data for Rwanda, there are large spatiotemporal gaps [10-12, 28], and no clear trend is discernible (Table 1). However, high prevalence of the confirmed artemisinin resistance marker $561 \mathrm{H}$ at two sites (Masaka and Rukara) are worrisome, especially as samples have been collected in 2018, and the current situation could be worse. Moreover, the prevalence of this marker has increased from 7 to $20 \%$ in Masaka between 2015 and 2018 (Table 1), even though the small sample size does not allow for definitive conclusions, but it is likely that the prevalence is even higher now, and only routine molecular monitoring could accurately assess the trend.

\section{Molecular routine surveillance to inform TES}

Molecular routine surveillance should not only be conducted in a few sentinel sites, but rather on a large network of health facilities to capture the complex spatial dynamics of evolving resistance [29]. Samples collected from patients attending selected health facilities in the different regions of a country, should be analysed on a regular basis and generated data used to map the

Table 1 Prevalence of PfKelch13 mutations associated with artemisinin resistance in five different sites in Rwanda from 2012 to 2019

\begin{tabular}{|c|c|c|c|c|c|c|c|c|c|}
\hline Study site & Reference & $\begin{array}{c}\text { Study } \\
\text { year(s) }\end{array}$ & $441 \mathrm{~L}$ & 449A & $469 Y$ & $469 \mathrm{~F}$ & $561 \mathrm{H}$ & 574L & $675 \mathrm{~V}$ \\
\hline $\begin{array}{l}\text { Nyarurema } \\
(\mathrm{n}=73)\end{array}$ & [2] & $2012-2015$ & $\begin{array}{c}0 \\
(0 \%)\end{array}$ & $\begin{array}{c}0 \\
(0 \%)\end{array}$ & $\begin{array}{c}0 \\
(0 \%)\end{array}$ & $\begin{array}{c}1 \\
(1 \cdot 3 \%)\end{array}$ & $\begin{array}{c}0 \\
(0 \%)\end{array}$ & $\begin{array}{c}0 \\
(0 \%)\end{array}$ & $\begin{array}{c}0 \\
(0 \%)\end{array}$ \\
\hline $\begin{array}{l}\text { Masaka } \\
(n=134)\end{array}$ & {$[2]$} & $2012-2015$ & $\begin{array}{c}0 \\
(0 \%) \\
\end{array}$ & $\begin{array}{c}0 \\
(0 \%) \\
\end{array}$ & $\begin{array}{c}0 \\
(0 \%)\end{array}$ & $\begin{array}{c}0 \\
(0 \%)\end{array}$ & $\begin{array}{c}1 \\
(0 \cdot 7 \%)\end{array}$ & $\begin{array}{c}0 \\
(0 \%)\end{array}$ & $\begin{array}{c}0 \\
(0 \%)\end{array}$ \\
\hline $\begin{array}{l}\text { Masaka } \\
(\mathrm{n}=257)\end{array}$ & {$[2]$} & $2013-2015$ & $\begin{array}{c}0 \\
(0 \%)\end{array}$ & $\begin{array}{c}0 \\
(0 \%)\end{array}$ & $\begin{array}{c}1 \\
(0.5 \%)\end{array}$ & $\begin{array}{c}0 \\
(0 \%)\end{array}$ & $\begin{array}{c}19 \\
(7 \cdot 4 \%)\end{array}$ & $\begin{array}{c}1 \\
(0.5 \%)\end{array}$ & $\begin{array}{c}0 \\
(0 \%)\end{array}$ \\
\hline $\begin{array}{l}\text { Huye } \\
(\mathrm{n}=66)\end{array}$ & {$[16]$} & 2015 & $\begin{array}{c}0 \\
(0 \%) \\
\end{array}$ & $\begin{array}{c}0 \\
(0 \%) \\
\end{array}$ & $\begin{array}{c}0 \\
(0 \%) \\
\end{array}$ & $\begin{array}{c}0 \\
(0 \%) \\
\end{array}$ & $\begin{array}{c}0 \\
(0 \%) \\
\end{array}$ & $\begin{array}{c}3 \\
(4 \cdot 5 \%) \\
\end{array}$ & $\begin{array}{c}3 \\
(4 \cdot 5 \%) \\
\end{array}$ \\
\hline $\begin{array}{l}\text { Masaka } \\
(\mathrm{n}=51)\end{array}$ & {$[3]$} & 2018 & $\begin{array}{c}1 \\
(2 \%)\end{array}$ & $\begin{array}{c}1 \\
(2 \%)\end{array}$ & $\begin{array}{c}0 \\
(0 \%)\end{array}$ & $\begin{array}{c}1 \\
(2 \%)\end{array}$ & $\begin{array}{c}10 \\
(20 \%)\end{array}$ & $\begin{array}{c}0 \\
(0 \%)\end{array}$ & $\begin{array}{c}0 \\
(0 \%)\end{array}$ \\
\hline $\begin{array}{l}\text { Rukara } \\
(n=82)\end{array}$ & [3] & 2018 & $\begin{array}{c}3 \\
(4 \%)\end{array}$ & $\begin{array}{c}3 \\
(4 \%)\end{array}$ & $\begin{array}{c}0 \\
(0 \%)\end{array}$ & $\begin{array}{c}3 \\
(4 \%)\end{array}$ & $\begin{array}{c}8 \\
(22 \%)\end{array}$ & $\begin{array}{c}2 \\
(1 \%)\end{array}$ & $\begin{array}{c}0 \\
(0 \%)\end{array}$ \\
\hline $\begin{array}{l}\text { Bugarama } \\
(\mathrm{n}=85)\end{array}$ & [3] & 2018 & $\begin{array}{c}1 \\
(1 \%)\end{array}$ & $\begin{array}{c}1 \\
(1 \%)\end{array}$ & $\begin{array}{c}1 \\
(1 \%)\end{array}$ & $\begin{array}{c}1 \\
(1 \%)\end{array}$ & $\begin{array}{c}0 \\
(0 \%)\end{array}$ & $\begin{array}{c}0 \\
(0 \%)\end{array}$ & $\begin{array}{c}0 \\
(0 \%)\end{array}$ \\
\hline $\begin{array}{l}\text { Huye } \\
(n=66)\end{array}$ & [1] & 2019 & $\begin{array}{c}0 \\
(0 \%)\end{array}$ & $\begin{array}{c}0 \\
(0 \%)\end{array}$ & $\begin{array}{c}0 \\
(0 \%)\end{array}$ & $\begin{array}{c}3 \\
(4 \cdot 5 \%)\end{array}$ & $\begin{array}{c}3 \\
(4 \cdot 5 \%)\end{array}$ & $\begin{array}{c}0 \\
(0 \%)\end{array}$ & $\begin{array}{c}3 \\
(4 \cdot 5 \%) \\
\end{array}$ \\
\hline
\end{tabular}

Each colour represents data from the same sites 
spatiotemporal dynamics of molecular markers of interest [29-32]. The data could be then used to inform and calibrate mathematical models of malaria transmission aiming at guiding interventions strategies, for example to select the sites for TES, using specific thresholds for artemisinin and partner drug resistance markers prevalence, to assess either delayed parasite clearance or treatment failure, respectively [21,33]. Indeed, it is difficult to predict where resistance will emerge, and a more flexible scheme with rotating sites for TES based on molecular markers prevalence and models prediction may be more appropriate for early detection of resistance. Mathematical models could be used as well to predict when treatment failure could occur based on the molecular markers prevalence, giving more time for policymakers to prepare the change in anti-malarial drug treatment policy [34, 35].

Logistically, sample collection would require only dried blood spots collection at selected health centres when patients have a confirmed malaria diagnosis. The molecular analysis could be centralized at regional, national or sub-regional laboratory to maximize the cost effectiveness of the surveillance system [36]. With the increasing availability of high throughput techniques and assays for molecular markers of resistance genotyping in malaria endemic countries, there is an opportunity to strengthen the capacity of National Malaria Control Programmes (NMCPs) for molecular monitoring of anti-malarial drug resistance [37, 38]. Cross-border collaboration is also critical, especially in regions such as the Great Lakes (Fig. 1), where validated resistance markers have been detected in different countries, including Rwanda, Democratic Republic of the Congo, Kenya, and Tanzania (Fig. 1). Regional monitoring is key to track resistance, as parasites will spread quickly from one country to another. The establishment of regional reference laboratories associated with regional data repositories could facilitate the prompt detection of resistance and early implementation of mitigation strategies; and the malaria community must leverage on the different initiatives on the continent to improve access to the infrastructure and technical expertise for high throughput molecular analyses [39].

\section{Ex vivo assays: a useful,but difficult tool to implement}

Ex vivo assays have played an important role in monitoring artemisinin resistance in the GMS [3, 15, 40, 41]. Even though they are often used for phenotypic assays to validate molecular markers of resistance, where available they can be useful to monitor resistance. Indeed, as for molecular markers, immunity is not a confounding

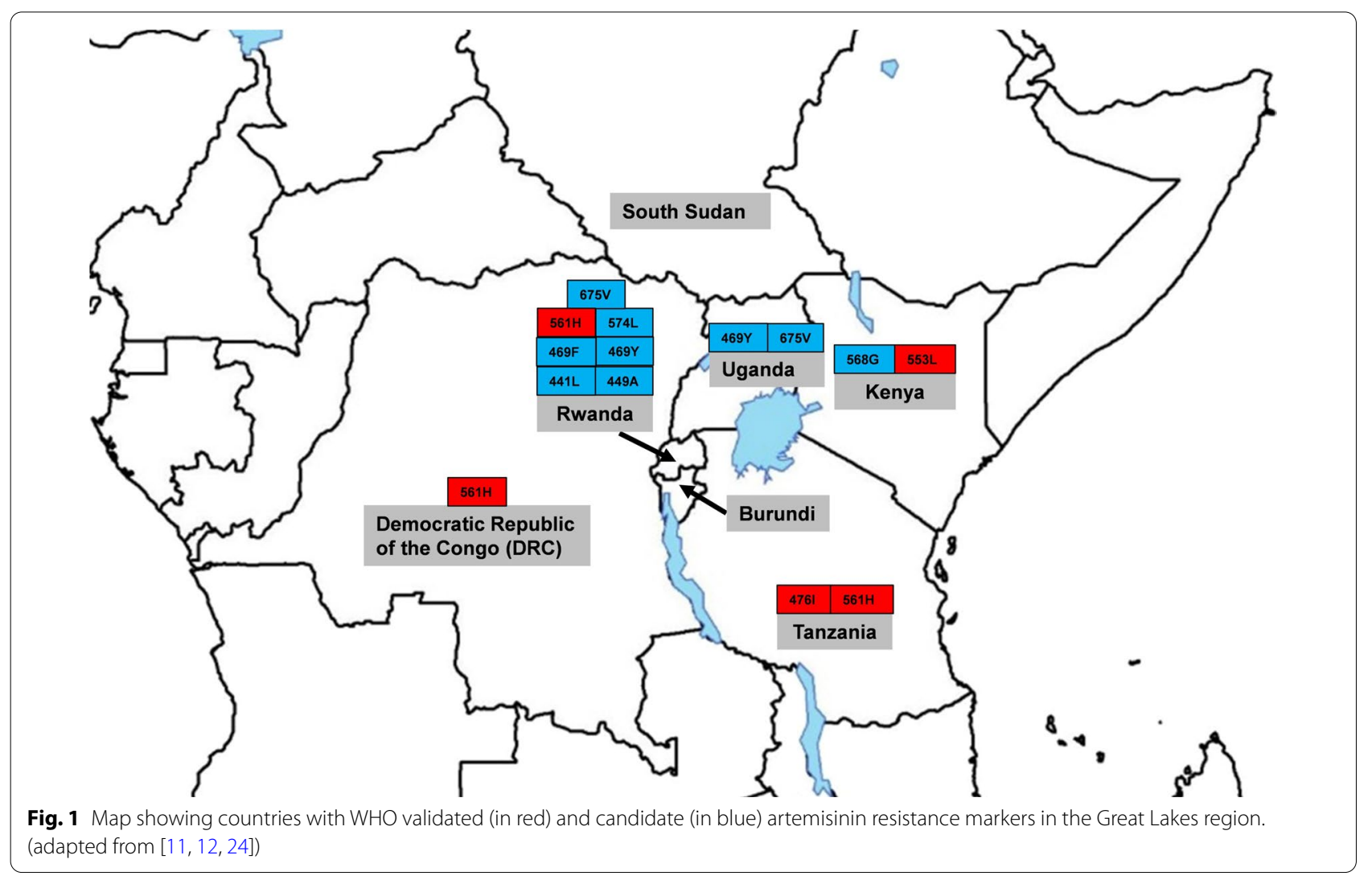


factor for ex vivo assays, even though parasite culture may reduce the complexity of the infection by preferentially selecting specific clones. However, ex vivo assays can be a valuable tool for drugs with no validated molecular markers, such as lumefantrine and pyronaridine, the former being the partner drug of the most widely used $\mathrm{ACT}$, and the latter, the most recent ACT partner drug approved by the WHO. Moreover, compared to molecular markers, ex vivo assays are difficult to implement, as fresh blood is required for parasite culture and the high intra and inter-assays variability limits their ability for spatiotemporal dynamics assessment [42].

\section{Conclusions}

Anti-malarial drug resistance is a serious threat to malaria control and elimination, and resistance monitoring is crucial to maintain the high efficacy of the current anti-malarial drugs. Anti-malarial drug efficacy monitoring schemes should take the full advantage of molecular and ex vivo culture techniques, as they may be the most appropriate tools to provide early warning signals of antimalarial drug resistance in high transmission settings. Reinforcing routine molecular surveillance programme could help detecting the emergence and spread of artemisinin and partner drug resistance at an earlier stage, before it translates to treatment failures.

\section{Abbreviations}

ACT: Artemisinin-based combination therapy; GMS: Greater Mekong Subregion; NMCP: National Malaria Control Programme; TES: Therapeutic efficacy study; WHO: World Health Organization.

\section{Acknowledgements}

I would like to thank my colleagues for fruitful discussions.

\section{Authors' contribution}

CN designed and wrote this opinion article. The author read and approved the final manuscript

\section{Author's informations}

CN was trained in molecular epidemiology at the Université de Neuchâtel and Swiss Tropical and Public health institute in Switzerland. He has more than 17 years' experience in malaria research going from basic to translational and implementation research, mainly on anti-malarial drug efficacy, anti-malarial drug resistance and mode of action, including postdoctoral experience at the University of California San Francisco, and University of Oxford with the WorldWide Antimalarial Resistance Network (WWARN). He is currently leading the malaria genotyping group in the Diagnostics Unit at the Swiss Tropical and Public Health Institute.

\section{Funding}

None.

Availability of data and materials

Not applicable.

\section{Declarations}

Ethics approval and consent to participate Not applicable.
Consent for publication

Not applicable.

\section{Competing interests}

The author declares no competing interests.

\section{Author details}

'Department of Medicine, Swiss Tropical and Public Health Institute, Socinstrasse 57, 4002 Basel, Switzerland. ${ }^{2}$ University of Basel, P.O. Box, 4003 Basel, Switzerland.

Received: 6 July 2021 Accepted: 5 October 2021

Published online: 13 October 2021

\section{References}

1. Ariey F, Witkowski B, Amaratunga C, Beghain J, Langlois AC, Khim N, et al. A molecular marker of artemisinin-resistant Plasmodium falciparum malaria. Nature. 2014;505:50-5.

2. Amaratunga C, Lim P, Suon S, Sreng S, Mao S, Sopha C, et al. Dihydroartemisinin-piperaquine resistance in Plasmodium falciparum malaria in Cambodia: a multisite prospective cohort study. Lancet Infect Dis. 2016;16:357-65.

3. Duru V, Khim N, Leang R, Kim S, Domergue A, Kloeung N, et al. Plasmodium falciparum dihydroartemisinin-piperaquine failures in Cambodia are associated with mutant K13 parasites presenting high survival rates in novel piperaquine in vitro assays: retrospective and prospective investigations. BMC Med. 2015;13:305.

4. Leang R, Taylor WR, Bouth DM, Song L, Tarning J, Char MC, et al. Evidence of Plasmodium falciparum malaria multidrug resistance to artemisinin and piperaquine in Western Cambodia: dihydroartemisinin-piperaquine open-label multicenter clinical assessment. Antimicrob Agents Chemother. 2015;59:4719-26.

5. Lon C, Manning JE, Vanachayangkul P, So M, Sea D, Se Y, et al. Efficacy of two versus three-day regimens of dihydroartemisinin-piperaquine for uncomplicated malaria in military personnel in northern Cambodia: an open-label randomized trial. PLoS One. 2014;9:e93138.

6. Saunders DL, Vanachayangkul P, Lon C, US Army Military Malaria Research Program, National Center for Parasitologym Entomology and Malaria Control. Royal Cambodian Armed Forces. Dihydroartemisinin-piperaquine failure in Cambodia. N Engl J Med. 2014;371:484-5.

7. Spring MD, Lin JT, Manning JE, Vanachayangkul P, Somethy S, Bun R, et al. Dihydroartemisinin-piperaquine failure associated with a triple mutant including kelch13 C580Y in Cambodia: an observational cohort study. Lancet Infect Dis. 2015;15:683-91.

8. WHO. Status report on artemisinin resistance and ACT efficacy. Geneva, World Health Organization. 2018. https://www.who.int/malaria/publi cations/atoz/artemisinin-resistance-august2018/en/.

9. Witkowski B, Khim N, Kim S, Domergue A, Duru V, Menard D. Multiple and successive treatment failures in a patient infected by Plasmodium falciparum in Cambodia and treated by dihydroartemisinin-piperaquine (in French). Bull Soc Pathol Exot. 2016;109:87-90.

10. Bergmann C, van Loon W, Habarugira F, Tacoli C, Jager JC, Savelsberg $D$, et al. Increase in kelch 13 polymorphisms in Plasmodium falciparum, Southern Rwanda. Emerg Infect Dis. 2021;27:294-6.

11. Uwimana A, Legrand $E$, Stokes BH, Ndikumana JM, Warsame M, Umulisa $\mathrm{N}$, et al. Emergence and clonal expansion of in vitro artemisinin-resistant Plasmodium falciparum kelch13 R561 H mutant parasites in Rwanda. Nat Med. 2020;26:1602-8.

12. Uwimana A, Umulisa N, Venkatesan M, Svigel SS, Zhou Z, Munyaneza T, et al. Association of Plasmodium falciparum kelch13 R561H genotypes with delayed parasite clearance in Rwanda: an open-label, single-arm, multicentre, therapeutic efficacy study. Lancet Infect Dis. 2021;21:1120-8.

13. WHO. Methods for surveillance of antimalarial drug efficacy. Geneva: World Health Organization; 2009. https://apps.who.int/iris/handle/10665/ 44048.

14. Imwong M, Dhorda M, Myo Tun K, Thu AM, Phyo AP, Proux S, et al. Molecular epidemiology of resistance to antimalarial drugs in the Greater Mekong subregion: an observational study. Lancet Infect Dis. 2020;20:1470-80 
15. Witkowski B, Duru V, Khim N, Ross LS, Saintpierre B, Beghain J, et al. A surrogate marker of piperaquine-resistant Plasmodium falciparum malaria: a phenotype-genotype association study. Lancet Infect Dis. 2017; 17:174-83.

16. Ataide R, Ashley EA, Powell R, Chan JA, Malloy MJ, O'Flaherty K, et al. Host immunity to Plasmodium falciparum and the assessment of emerging artemisinin resistance in a multinational cohort. Proc Natl Acad Sci USA. 2017;114:3515-20.

17. Ataide R, Powell R, Moore K, McLean A, Phyo AP, Nair S, et al. Declining transmission and immunity to malaria and emerging artemisinin resistance in Thailand: a longitudinal study. J Infect Dis. 2017;216:723-31.

18. Lopera-Mesa TM, Doumbia S, Chiang S, Zeituni AE, Konate DS, Doumbouya $\mathrm{M}$, et al. Plasmodium falciparum clearance rates in response to artesunate in Malian children with malaria: effect of acquired immunity. J Infect Dis. 2013;207:1655-63.

19. White NJ, Pongtavornpinyo W. The de novo selection of drug-resistant malaria parasites. Proc Biol Sci. 2003;270:545-54.

20. White NJ, Pongtavornpinyo W, Maude RJ, Saralamba S, Aguas R, Stepniewska K, et al. Hyperparasitaemia and low dosing are an important source of anti-malarial drug resistance. Malar J. 2009:8:253.

21. Whitlock AOB, Juliano JJ, Mideo N. Immune selection suppresses the emergence of drug resistance in malaria parasites but facilitates its spread. PLoS Comput Biol. 2021;17:e1008577.

22. McCollum AM, Poe AC, Hamel M, Huber C, Zhou Z, Shi YP, et al. Antifolate resistance in Plasmodium falciparum: multiple origins and identification of novel dhfr alleles. J Infect Dis. 2006;194:189-97.

23. Vinayak S, Alam MT, Mixson-Hayden T, McCollum AM, Sem R, Shah NK, et al. Origin and evolution of sulfadoxine resistant Plasmodium falciparum. PLoS Pathog. 2010;6:e1000830.

24. Kayiba NK, Yobi DM, Tshibangu-Kabamba E, Tuan VP, Yamaoka Y, Devleesschauwer B, et al. Spatial and molecular mapping of Pfkelch13 gene polymorphism in Africa in the era of emerging Plasmodium falciparum resistance to artemisinin: a systematic review. Lancet Infect Dis. 2021;21:e82-92

25. Nsanzabana C, Hastings IM, Marfurt J, Muller I, Baea K, Rare L, et al. Quantifying the evolution and impact of antimalarial drug resistance: drug use, spread of resistance, and drug failure over a 12-year period in Papua New Guinea. J Infect Dis. 2010;201:435-43.

26. Nsanzabana C. Resistance to artemisinin combination therapies (ACTs): do not forget the partner drug! Trop Med Infect Dis. 2019;4:26.

27. Tun KM, Jeeyapant A, Myint AH, Kyaw ZT, Dhorda M, Mukaka M, et al. Effectiveness and safety of 3 and 5 day courses of artemether-lumefantrine for the treatment of uncomplicated falciparum malaria in an area of emerging artemisinin resistance in Myanmar. Malar J. 2018;17:258.

28. Tacoli C, Gai PP, Bayingana C, Sifft K, Geus D, Ndoli J, et al. Artemisinin resistance-associated K13 polymorphisms of Plasmodium falciparum in Southern Rwanda, 2010-2015. Am J Trop Med Hyg. 2016;95:1090-3.

29. Aydemir O, Janko M, Hathaway NJ, Verity R, Mwandagalirwa MK, Tshefu AK, et al. Drug-resistance and population structure of Plasmodium falciparum across the Democratic Republic of Congo using highthroughput molecular inversion probes. J Infect Dis. 2018;218:946-55.

30. Ehrlich HY, Bei AK, Weinberger DM, Warren JL, Parikh S. Mapping partner drug resistance to guide antimalarial combination therapy policies in sub-Saharan Africa. Proc Natl Acad Sci USA. 2021;118:e2100685118.

31. Ehrlich HY, Jones J, Parikh S. Molecular surveillance of antimalarial partner drug resistance in sub-Saharan Africa: a spatial-temporal evidence mapping study. Lancet Microbe. 2020;1:e209-17.

32. Otienoburu SD, Suay I, Garcia S, Thomas NV, Srisutham S, Bjorkman A, et al. An online mapping database of molecular markers of drug resistance in Plasmodium falciparum: the ACT Partner Drug Molecular Surveyor. Malar J. 2019;18:12.

33. Hastings IM, Hardy D, Kay K, Sharma R. Incorporating genetic selection into individual-based models of malaria and other infectious diseases. Evol Appl. 2020;13:2723-39.

34. malERA Refresh Consultative Panel on Combination Interventions and Modelling. malERA: an updated research agenda for combination interventions and modelling in malaria elimination and eradication. PLoS Med. 2017;14:e1002453.

35. Slater HC, Griffin JT, Ghani AC, Okell LC. Assessing the potential impact of artemisinin and partner drug resistance in sub-Saharan Africa. Malar J. 2016;15:10.

36. Nsanzabana C. Strengthening surveillance systems for malaria elimination by integrating molecular and genomic data. Trop Med Infect Dis. 2019;4:139.

37. Dalmat R, Naughton B, Kwan-Gett TS, Slyker J, Stuckey EM. Use cases for genetic epidemiology in malaria elimination. Malar J. 2019;18:163.

38. Ndiaye YD, Hartl DL, McGregor D, Badiane A, Fall FB, Daniels RF, et al. Genetic surveillance for monitoring the impact of drug use on Plasmodium falciparum populations. Int J Parasitol Drugs Drug Resist. 2021;17:12-22.

39. Inzaule SC, Tessema SK, Kebede Y, Ogwell Ouma AE, Nkengasong JN. Genomic-informed pathogen surveillance in Africa: opportunities and challenges. Lancet Infect Dis. 2021;21:e281-9.

40. Witkowski B, Amaratunga C, Khim N, Sreng S, Chim P, Kim S, et al. Novel phenotypic assays for the detection of artemisinin-resistant Plasmodium falciparum malaria in Cambodia: in-vitro and ex-vivo drug-response studies. Lancet Infect Dis. 2013;13:1043-9.

41. Witkowski B, Khim N, Chim P, Kim S, Ke S, Kloeung N, et al. Reduced artemisinin susceptibility of Plasmodium falciparum ring stages in western Cambodia. Antimicrob Agents Chemother. 2013;57:914-23.

42. Nsanzabana C, Djalle D, Guerin PJ, Menard D, Gonzalez IJ. Tools for surveillance of anti-malarial drug resistance: an assessment of the current landscape. Malar J. 2018;17:75.

\section{Publisher's Note}

Springer Nature remains neutral with regard to jurisdictional claims in published maps and institutional affiliations.

\footnotetext{
Ready to submit your research? Choose BMC and benefit from:

- fast, convenient online submission

- thorough peer review by experienced researchers in your field

- rapid publication on acceptance

- support for research data, including large and complex data types

- gold Open Access which fosters wider collaboration and increased citations

- maximum visibility for your research: over 100M website views per year
}

At $\mathrm{BMC}$, research is always in progress.

Learn more biomedcentral.com/submissions 